\title{
Labrando la Tierra Prometida: estudio de las representaciones de la naturaleza y el espacio en Los gauchos judíos de Alberto Gerchunoff
}

\author{
TILLING THE PROMISED LAND: A STUDY OF THE DIFFERENT REPRESENTATIONS \\ OF NATURE AND SPACE IN ALBERTO GERCHUNOFF'S LOS GAUCHOS JUDÍOS
}

\author{
LAVRANDO A TERRA PROMETIDA: UM ESTUDO DAS REPRESENTAÇÕES DA \\ NATUREZA E DO ESPAÇO EM LOS GAUCHOS JUDÍOS DE ALBERTO GERCHUNOFF.
}

\author{
Juan Aguerre *1
}

juenh77@gmail.com

\begin{abstract}
Resumen
En este artículo se propone un estudio de las distintas representaciones de la naturaleza, del mundo vegetal en particular, y del espacio en la novela Los gauchos judíos de Alberto Gerchunoff. En ella se narra la llegada de un grupo de judíos a la provincia de Entre Ríos a fines del siglo XIX, huyendo de la Rusia zarista donde fueron víctimas de marginación y hostigamientos por parte de los cosacos. La importancia de la tierra para la comunidad se revela en los epígrafes iniciales: "Los más fuertes y más grandes varones de Judea trabajan la tierra; cuando el pueblo elegido cayó en cautividad se dedicó a oficios viles y peligrosos, perdiendo la gracia de Dios". El marco teórico propuesto es un enfoque reciente para la Teoría Literaria, como es la convergencia entre la ecocrítica con los estudios del espacio, o "giro espacial" en las Humanidades. Una postura crítica con un pie en la literatura y otro en la tierra, una negociación entre lo humano y lo no-humano. Para ellos el trabajo de la tierra y sus frutos les procura alimento, subsistencia y además una dignificación, les otorga la gracia divina. Pero la naturaleza les va a exigir algo a cambio y ese aspecto se alinea con los planteos de Stefano Mancuso o Michael Pollan, en que la existencia de una reciprocidad en la relación humano-vegetal es ineludible. En línea con el pensamiento sarmientino, Gerchunoff va a plantear el tema del espacio y delimitará un mapa que divide a la comunidad judía de lo que es el desierto que la rodea. Un espacio ocupado por lo desconocido y hostil, que al igual que en Facundo estará habitada por el gaucho. Una suerte de alteridad de la que no pueden escapar puesto que necesitan de él como aliado en el oficio pastoril. De esa tensión no estará exento el relato y a ella, en parte, se debe el título de la novela.
\end{abstract}

Palabras clave: ecocrítica, estudios latinoamericanos, gauchos judíos, diáspora

1 * Facultad de Humanidades y Ciencias de la Educación. Universidad de la República

Tekoporá ${ }^{\circledR}$. Centro Universitario de la Región Este. Universidad de la República (C) Aguerre. (2021)

Este es un artículo de Acceso Abierto distribuido bajo licencia Creative Commons (CC BY NC 4.0) 
judía, otredad

\begin{abstract}
The purpose of this article is a study of the different representations of Nature (the vegetal world in particular) and space in Alberto Gerchunoff's novel Los gauchos judíos. The novel describes the arrival of a Jewish community in the Province of Entre Ríos at the end of 19th Century, escaping from tsarist Russia where they were victims of harassment by Cossacks. The importance of the land is key to the Jewish immigrants and it is revealed by the initial headings of the book: "The stronger and greatest Jewish men work the land; when the chosen people fell into captivity, they went into vile and dangerous trades, losing the grace of God." The proposed theoretical framework is a recent literary approach: the convergence between ecocriticism and the spatial turn in the Humanities. This critical position, with one foot in literature and another on the land, allows a negotiation between the human and the non-human. For these Jewish settlers, the work of the land and its fruits provides them not only with food and sustenance, but also a dignification, the divine grace. But nature will demand something of them in return. This is what Michael Pollan and Stefano Mancuso propose, that the existence of a reciprocity in the human-plant relationship is unavoidable. In line with Sarmiento's thinking, Gerchunoff raises the issue of space and outlines a map that divides the jewish community from the surrounding desert, a space occupied by the unknown and the hostile that-like in Facundo-will be inhabited by the gaucho. This is a kind of alterity from which they will not be able to escape because they need the gaucho in order to learn about pastoral work. The story is not exempt from this tension and Los gauchos judíos owes its very title to it.
\end{abstract}

Keywords: ecocriticism, Latin American Studies, Jewish gauchos, Otherness, Jewish diaspora

\title{
Resumo
}

O artigo propõe um estudo das diferentes representações da natureza, em particular do mundo vegetal e do espaço no romance Los gauchos judíos, de Alberto Gerchunoff. Nesta obra narra-se a chegada de um grupo de judeus à província de Entre Ríos no final do século XIX, fugindo da Rússia czarista onde foram vítimas da marginalização e perseguição pelos cossacos. A importância da terra para aquela comunidade é revelada já nas epígrafes iniciais: "Os maiores e mais fortes homens da Judéia trabalham a terra; quando o povo escolhido caiu em cativeiro, se dedicou a ofícios vis $e$ perigosos, perdendo a graça de Deus". O referencial teórico proposto é uma abordagem recente para a Teoria Literária, assim como a convergência entre "ecocriticismo" e estudos espaciais das Humanidades. Uma postura crítica com um pé na literatura e outro na terra, ou, ainda, uma negociação entre o humano e o não humano. Para eles o trabalho na terra e seus frutos lhes fornece alimento, subsistência e dignidade. Lhes dá a graça divina. Mas a natureza também exige algo deles em troca e esse aspecto está alinhado com as propostas de Stefano Mancuso ou Michael Pollan, nas quais a existência de uma reciprocidade na relação homem-planta é inevitável. Gerchunoff levantará ademais a questão do espaço e 
delimitará um mapa que divide a comunidade judaica, do deserto circundante, em linha com o pensamento de Sarmiento. Um espaço ocupado pelo desconhecido e hostil, que, como em Facundo, estará habitado pelo gaúcho. Uma sorte da qual não podem escapar, pois precisam dele como aliado na profissão pastoral. A história não estará isenta desta tensão e a isto se deve, em parte, o título do romance.

Palavras-chave: ecócrita, estudos latino-americanos, diáspora judaica, alteridade

\section{Introducción}

En el presente artículo se propone un estudio de las distintas representaciones de la naturaleza, en particular del mundo vegetal, y del espacio en la novela Los gauchos judíos de Alberto Gerchunoff, publicada por primera vez en 1910, año en que se celebró el primer Centenario argentino. En ella se narra la llegada de un grupo de judíos a la provincia de Entre Ríos durante la segunda mitad del siglo XIX, huyendo de la Rusia zarista donde fueron víctimas de marginación y hostigamientos por parte de los cosacos.

La naturaleza va a tener un lugar central en la novela, esto se puede evidenciar ya desde el comienzo, en los epígrafes con que se abre la narración. Primero, una referencia a las bendiciones cotidianas: "Bendito seas, Señor, Rey único de todos los pueblos, por haber creado los frutos que nos da la tierra y nos dan los árboles" (Gerchunoff, 2007, p. 43); y luego, unos versos tomados del Alegato de Rabussi: "Los más fuertes y más grandes varones de Judea trabajan la tierra; cuando el pueblo elegido cayó en cautividad se dedicó a oficios viles y peligrosos, perdiendo la gracia de Dios" (p. 43). Trabajar la tierra tenía un significado mucho más profundo que el mero exilio de un ambiente hostil en que estaban inmersos; era escapar, de algún modo, de las actividades viles, para desembarcar en un lugar donde vivir de los frutos de sus propias cosechas y ser bendecidos por ello.

Pero la llegada de los colonos respondía a un proyecto mayor, cuyos intereses coincidían con el mandato divino que quedaba de manifiesto en las escrituras talmúdicas. Ya desde antes de los movimientos independentistas hispanoamericanos, al pensar el sujeto que habitaría esos pueblos libres de los lazos que los unían a la Corona, ese "pequeño género humano" al que se refería Bolívar en su "Carta de Jamaica" (2009, p. 18), debía de trabajar la tierra, esa "fecunda zona" todavía tórrida, parafraseando los versos de Andrés Bello, porque en ella se escondían las riquezas que harían posible la emancipación. En la Argentina, ya independiente pero en plena construcción, a la que llegan las colonias hebraicas gracias a la mediación del barón de Hirsch, a partir de la década de 1860, estaba teniendo lugar una epopeya inmigratoria en pos de cumplir aquella máxima alberdiana de "gobernar es poblar"; poblar, sobre todo aquellos desiertos, aquel terreno salvaje, ingobernable, que se encontraba improductivo y que, a pesar de su nombre, estaba poblado, pero no por la civilización, sino por la barbarie, encarnada en la figura del gaucho, que serían como malas hierbas, plantas indisciplinadas, furtivas u oportunistas, que colonizan la tierra de nadie, 
como sostiene Beruete (2018). Una tierra sin cultivar o, como Clément Gilles la bautizó, un "tercer paisaje", espacios baldíos o improductivos que ponían en peligro los proyectos civilizatorios americanos (2007, p. 10).

La segunda parte de este trabajo tendrá como eje un análisis de la delimitación del mapa en donde Gerchunoff ubica a la colonia de Rajil, que con esfuerzo se alzó a manos de la comunidad judeoentrerriana, como un oasis rodeado por el desierto. Este tipo de abordaje responde al llamado spatial turn o "giro espacial" de las Humanidades en el análisis literario. Slawinski (1989) afirma que el espacio, considerado hasta el momento como una categoría de segundo orden respecto a, por ejemplo, la construcción temporal de la obra literaria, las reflexiones sobre la fábula en torno a la red de personajes o el interés suscitado en relación al narrador o al sujeto literario, ha pasado a constituir "el centro de la semántica de la obra y la base de otros ordenamientos que aparecen en ella” (p. 266). Aquellas categorías de primer orden se encuentran en una relación de interdependencia con el espacio. Llarena (2002), por su parte, hace especial hincapié en la importancia de la representación del espacio en la literatura hispanoamericana, debido a que ha sabido acompañar los procesos históricos más relevantes como una forma de construcción de identidad. Respecto al período de Independencia y al proceso postcolonial, Llarena (2002) afirma que "para conquistar de nuevo su naturaleza enajenada, América debía despojarse primero de las falsas imágenes heredadas por una tradición asimismo extraña" (p. 43) y para lograrlo el espacio es el eje principal, "un punto de anclaje y una imagen fundacional de la realidad" (p. 44). La relación con el espacio determina hábitos psicológicos, perceptivos y culturales, y es por eso que, según Bachelard (1978), el espacio imaginado se transforma en espacio vivido dando lugar a un verdadero sistema de referencias para la crítica artística (p. 23). El personaje es uno con el espacio, el estar determina al ser, condicionando su carácter (p. 32).

Ese espacio imaginado, en términos de la novela, estará basado en parte por el relato bíblico, por la construcción imaginaria del Nuevo Mundo que todavía persistía en Occidente, esa tierra fecunda de interminables frutos, pero también por el pensamiento sarmientino y su visión del territorio pampeano, con el que Gerchunoff estará íntimamente ligado y en muchos pasajes reproducirá, sobre todo al momento de delimitar el espacio que ocupa el pueblo de Rajil y sus alrededores.

En el texto se pueden encontrar ejemplos de "topofilia", o un arraigo afectivo al espacio en que se habita como también "topofobia", percepción de hostilidad por el entorno, sobre todo a partir de la relación de otredad que existe entre judíos y criollos. Lo cual no es extraño ya que como indica Oliva Cruz (2010), no es poco frecuente que ambos conceptos se entremezclen cuando estamos en presencia de una "literatura escrita desde la distancia física de la tierra de nacimiento y la cercanía artificial de la tierra de acogida" (pp. 294-295). Los gauchos judíos no va a ser un testimonio literario ajeno a las características de la literatura del desarraigo que define Oliva Cruz y el fin último se va a encontrar en la construcción de una identidad híbrida, que se articuló a los requisitos ideológico-culturales del Centenario argentino y sus exigencias de homogeneidad, lo que va a justificar el oxímoron de "gaucho judío" presente en el título que dio el autor a su obra. Veremos luego que este aspecto forma parte de lo que Oliva Cruz llamó "la paradoja 
del emigrante", es decir, ser capaz de conversar y debatir con opuestos culturales muchas veces excluyentes, como es el caso del gaucho y el judío.

\section{El exilio: de lo apocalíptico a lo pastoril}

En el primer capítulo, Gerchunoff (2007) nos muestra a la futura colonia judía antes de arribar a las tierras entrerrianas, en la ciudad de Tulchin: "Las noticias de América llenaban de fantasía el alma de los judíos" (p. 43). Fue entonces cuando el Dain, rabí Jehuda Anakroi, hace un viaje a París para convenir con los hombres del barón de Hirsch la organización de las colonias hebreas en Argentina.

La imagen que tenían de ese nuevo mundo era, para sus términos, idílica: "Es una tierra donde todos trabajan y el cristiano no nos odiará, porque ahí el cielo es distinto, y en su alma habitan la piedad y la justicia" (Gerchunoff, 2007, p. 44). La ilusión no estaba puesta solamente en huir de una situación hostil en la cual se encontraba inmerso el pueblo judío, bajo el hostigamiento de los cosacos en la Rusia del zar, no era solamente huir de los pogroms, sino que había algo más; era dejar de lado los oficios viles a los que eran sometidos, ya que como sucedió en España, antes de la expulsión ordenada por los Reyes Católicos, al judío le estaba prohibido, entre otros oficios, trabajar la tierra. Para el rabino Tolno, la tierra española hubiera llegado a ser la "más codiciada si sobre ella no pesara la maldición de la Sinagoga" (p. 45); allí donde "los judíos dejaron de cultivar la tierra y de cuidar a sus ganados" (p. 45) y, como se especifica en el Zeroim, el primer libro del Talmud, cuando se refiere a la vida en el campo, "es la única saludable y digna de la gracia de Dios" (p. 45). Entonces, al vislumbrarse la posibilidad de emigrar a tierras argentinas, aquellas palabras "Sion está allí donde reina la alegría y la paz" (p. 45), resonaron en la cabeza del Dain y le hicieron olvidar la vuelta a Jerusalem y empezar a considerar esta nueva Tierra Prometida, donde podían volver, finalmente, a labrar la tierra y recibir la bendición de Dios, ya que, como insiste el rabí Jehuda Anakroi, citando la Ley Escrita, "solo los que viven de su ganado y de su siembra tienen el alma pura y merecen la eternidad del Paraíso" (pp. 45-46).

Greg Garrard (2012) propone en su libro Ecocriticism, una lectura retórica de la cultura (p. 8), es decir, se centra en los efectos que un discurso puede producir y de qué manera es capaz de hacerlo. Para ello se va a servir de una serie de tropos: lo pastoral, lo salvaje y lo apocalíptico, siendo éstos distintas formas de imaginar, construir o presentar a la naturaleza. El primero, lo pastoril o pastoral, representa una suerte de respuesta poética del Romanticismo a la Revolución Industrial y de alguna forma ha moldeado la construcción de la naturaleza en el imaginario colectivo (p. 37). Entre las tres manifestaciones pastorales que distingue Garrard en la tradición literaria, una de ellas representa la idealización de la vida rural, el idilio bucólico, donde reina la paz y la abundancia en contraposición con la frenética, corrupta e impersonal vida urbana.

Cabe destacar el momento en el cual el rabí Jehuda Anakroi hace mención acerca de abandonar la ciudad de Tulchin, abandonar los oficios viles, para llegar al territorio argentino y poder vivir de la vida pastoril, para luego añadir enfáticamente: "retornaremos a nuestra existencia anterior" (Gerchunoff, 2007, p. 46). Este pasaje muestra una visión elegíaca, lo que para Garrard significa el 
retorno "to a vanished past with a sense of nostalgia" (Garrard, 2012, p. 42) 2, que, en la concepción judeo-cristiana, suele connotar "an elegy of lost pastoral bounty and innocence" (p. 42) ${ }^{3}$. Santiago Beruete (2018), en su libro Verdolatría, se detiene en el concepto de la Arcadia griega, lugar utópico que es donde, según Schopenhauer, todos hemos nacido. Inspirados en Teócrito y Virgilio, los poetas renacentistas retrataban en sus versos ese "paraíso pastoril, de rústica simplicidad y primitiva belleza" (p. 35). Sin embargo, explica Beruete, aquel paraíso "nunca existió más que en la exaltada fantasía de los literatos y artistas" (p. 35) y no responde a otra cosa que al anhelo del retorno a la pureza de los orígenes, nostalgia de lo primitivo y un "impulso de huir de lo real en pos de la inocencia primordial” (p. 35). Y es que esa visión de la Tierra Prometida, así como de la Arcadia griega, está mediada por relatos.

Volviendo a los paradigmas de Garrard, el primer capítulo de Los gauchos judíos describe aquello que entraría en la categoría de "lo apocalíptico". Se abre con una detallada descripción de la situación en Rusia:

[E]ra el tiempo en que las leyes excepcionales se multiplicaban en el santo imperio de las Rusias. Las picas de los cosacos demolían sinagogas antiguas y los viejos santuarios traídos de Alemania, [...] en cuyo remate resplandecía el bitriángulo salomónico, eran conducidos por las calles en los carros municipales. (Gerchunoff, 2007, p. 43)

Para Garrard, "lo apocalíptico" se refiere a la concepción del fin de la historia humana, que es, al mismo tiempo, una revelación, el hecho de quitar el velo, así como la lucha entre el bien y el mal, la consumación de los tiempos. Tiene una relación directa con la fe, presencia de todo lo que signifique lo mesiánico, la salvación. Existe una ambivalencia en esta distopía, ya que supone una destrucción que salva un núcleo mínimo capaz de generar un futuro mejor y Gerchunoff, si bien describe la terrible situación del pueblo judío en la Rusia del zar, también vislumbra la esperanza de una existencia más justa en los preparativos para la emigración hacia el territorio argentino.

Hay un cambio radical en el segundo capítulo cuando lo pastoril irrumpe en la descripción de un paisaje bucólico que domina el amanecer de una fría mañana de invierno, que ya nos ubica en Provincia de Entre Ríos, con la colonia hebraica instalada:

El viento agita los distantes cardales. Hace frío. La mañana duerme en la pereza y una niebla muy fina vela los rayos de sol. La campiña blanquea bajo la escarcha, que se agranda como una ilusión de nieve. Más allá trabajan las vecinas y, en los momentos en que el viento calla, se oye el ruido que hace la ruedecita del arado. (Gerchunoff, 2007, p. 47)

Luego, el narrador continúa su relato desde la perspectiva de alguien que, como un niño, contempla asombrado todo lo que lo rodea. La colonia está dando sus primeros pasos en los trabajos agrícolas y de pastoreo, aprendiendo el oficio,

\footnotetext{
2 "a un pasado desaparecido con un sentido de nostalgia" [T. del A.].

3 "una elegía de una inocencia y una generosidad perdida" [T. del A.].
} 
tratando de comprender a la naturaleza. "Tenemos que marcar un nuevo trozo para labrarlo. Hemos enyugado los bueyes más dóciles. [...] Trazar los surcos iniciales constituye una tarea solemne. Lo comprenden todos" (Gerchunoff, 2007, p. 47). Estos primeros pasos al construir el surco, donde hay una colaboración entre lo humano y lo no-humano, resultan todo un acontecimiento para la recién inaugurada colonia judeoentrerriana: "el acto es demasiado interesante para que la familia quede en casa. Ahí está, pues, la madre con el jarro lleno de leche y las muchachas" (p. 48).

Esta transición entre lo apocalíptico y lo pastoril, debe pasar primero por la domesticación de lo salvaje, el tercer tropo del esquema de Garrard (2012). El paradigma de wilderness o "lo salvaje" da la pauta de una naturaleza que no ha sido contaminada por la civilización, por la mano del hombre. Representada por el yermo, el yuyal, el desierto, lo árido, las malas hierbas, aquello que está más allá de los campos cultivados (p. 67). Este concepto está también asociado a las mentes primitivas en contraste con la mentalidad civilizada, así como aquello que en la cultura judeocristiana, en el Génesis, se representa como lo que está al este del Edén, luego de la expulsión. Lugar del exilio (Garrard, 2012, p. 68), que es en definitiva el contexto en el que desembarcan los colonos y comienzan a labrar la Tierra Prometida, con la esperanza de poder gozar los frutos que la naturaleza es capaz de entregar.

Los primeros resultados empiezan a visualizarse:

Y la tierra, enfriada por el invierno, se abre exhalando un olor de fuerte humedad que el grupo familiar aspira como un aroma. La rueda única del arado canta el salmo de las siembras fecundas y, a lo lejos, el trapo rojo se despliega con orgullo de bandera. (Gerchunoff, 2007, p. 48)

El colono está domesticando al ganado, tratando de comprender a la naturaleza, ya que como afirma Francis Bacon, "la única manera de dominar a la naturaleza es obedecerla" (Bacon citado en Beruete, 2018, p. 113). Bacon, además, en Novum Organum, distingue distintos niveles de ambición, siendo el más elevado el que consiste en extender el imperio del hombre sobre la naturaleza ${ }^{4}$. Existe una negociación necesaria entre el hombre y la naturaleza, como afirma Pollan en The Botany of Desire, "we, too, are partners in a coevolutionary relationship, as indeed we have been ever since the birth of agriculture" (Pollan, 2001, p. 13) ${ }^{5}$. Entonces, Pollan se pregunta: "Did I choose to plant these potatoes, or did the potato make me do it? In fact, both statements are true" (p. 15) ${ }^{6}$. Es decir, la planta nos da sus frutos satisfaciendo nuestros deseos, pero antes estamos a su servicio, teniendo que brindarle los cuidados necesarios, razón por la cual podemos hablar de una negociación. También Beruete (2018) coincide en este punto al referirse a la

\footnotetext{
4 "Primum eorum, qui propriam potentiam in patria sua amplificare cupiunt; quod genus vulgare est et degener" (Bacon, Novum Organum, Liber Primus CXXIX).

5 "nosotros también somos socios en una relación de coevolución, como de hecho lo hemos sido desde el nacimiento de la agricultura" [T. del A.]

6 “¿He sido yo quien ha decidido plantar estas papas o son ellas las que me han hecho hacerlo? A decir verdad, ambas sentencias son correctas." [T. del A.]
} 
relación del hombre con los jardines, "estos no son únicamente una construcción material sino también una refinada creación intelectual, en la que, unidos por su profundo antagonismo, los seres humanos cultivan las plantas mientras se dejan cultivar por ellas" (p. 43). Esto, de algún modo, pone en entredicho al antropocentrismo, ya que como expresa Pollan,

we automatically think of domestication as something we do to other species, but it makes just as much sense to think of it as something certain plants and animals have done to us, a clever evolutionary strategy for advancing their own interest. (Pollan, 2001, p. $17)^{7}$

El invierno deja paso al otoño y el proceso de aprendizaje y de comunión con la naturaleza empieza a tener lugar, incluso en el uso del lenguaje, recurriendo a la metáfora verde: "con la aurora-la aurora de Dios alabada por el verbo de los santos rabinos-brotaban los diálogos del amanecer" (Gerchunoff, 2007, p. 49). Se presenta a Raquel, que se encuentra ordeñando a una vaca mientras "la aurora otoñal envuelve en su roja palidez al grupo y la moza deja ver, por la bata entreabierta, los senos redondos y duros que el sol de los fuertes veranos han dorado como frutos" (p. 49). Al describir sus trabajos pastoriles resaltando su belleza, el narrador evidenciará, en la composición del cuadro completo, rasgos divinos: "sus ojos tienen el azul que tiembla en las pupilas de la Virgen y la nariz resume en el bronceado arremango, los signos rotundos de la raza" (p. 50), consagrando al mismo tiempo, un carácter sacro producto de su imagen y sus labores:

Labriega, tú me recuerdas las mujeres augustas de la Escritura.[...] Raquel, tú eres Ester, Rebeca, Débora o Judith. Repites sus tareas bajo el cielo benévolo y tus manos atan las rubias gavillas cuando el sol incendia, en llamas de oro ondulante, las olas de trigo, sembrado por tus manos y bendecido por el ademán patriarcal de tu padre, que ya no es prestamista ni mártir, como en la Rusia del zar. (Gerchunoff, 2007, p. 50)

Nuevamente las labores pastoriles son exaltadas en contraposición con los oficios considerados impuros, que no tenían más opción que practicar en la Rusia zarista.

Dentro de este proceso de aprendizaje, se destaca un diálogo entre Efraím y Remigio, a este último se lo refiere como "peoncito", criollo que trabajaba en la casa del primero. Efraím le pregunta: “¿Rastreamos, Remigio?”, a lo que el peón responde: "No, don Efraím. Ha llovido demasiado; más vale arar" (Gerchunoff, 2007 , p. 49). Es decir, el colono recién asentado se sirve de los conocimientos del criollo, de su sabiduría respecto a los tiempos de la naturaleza, de cuándo es el mejor momento para hacer una determinada actividad, en esa negociación entre el hombre y lo vegetal, a la que hacía referencia Pollan. Según este,

\footnotetext{
7 "Nosotros asociamos automáticamente la domesticación como algo que hacemos a otras especies, pero tendría mucho más sentido pensar en ella como algo que ciertas plantas y animales han hecho con nosotros, una inteligente estrategia de evolución para alcanzar su propio interés" [T. del A.]
} 
We're unsure about our power in nature, its legitimacy, and its reality, and rightly so. Perhaps more than most, the farmer or the gardener understands that his control is always something of a fiction, depending as it does on luck and weather and much else that is beyond his control. (Pollan, 2001, p. 7)

La relación entre los integrantes de la colonia y los gauchos será tratada en detalle más adelante al mencionar la cuestión espacial, y el modo en el cual el mapa se va delimitando a lo largo del relato.

En los dos capítulos siguientes, que el autor tituló "La lluvia" y "La siesta", se percibe una armonía entre lo humano y lo no-humano, es como si ambos hubieran sabido acompasar sus tiempos y alcanzar una coexistencia armónica: "La tarde se extingue en la dulzura de la paz beatífica [...] los animales, conocedores de la hora, van aproximándose al corral. La colonia se recoge en el descanso" (Gerchunoff, 2007, p. 51).

Más adelante lo mismo sucederá en el episodio en que se celebra el shabbath, "día del santo reposo, día bendecido por los escritos rabínicos y saludado en las oraciones de Jehuda Halevi, el poeta" (p. 53). Se celebra, contemplándolo, el florecimiento de la tierra, los frutos de la cosecha y el modo en que la Tierra Prometida -ubicada ahora en Entre Ríos, en la colonia agrícola de Rajil, en la nueva Sion-, se ha transformado de aquel wilderness al que habían llegado, al paradigma de lo pastoral de Garrard. "Floridas están las huertas y verdes los campos sin fin" (p. 53). El descanso sabatino parece, además, ser respetado por sus animales: "En el potrero descansa el ganado. Los bueyes rumian y mueven sus cabezas pensativamente, y en sus cuernos la luz se quiebra en flechas azuladas. También para ellos el sábado es día bendito" (p. 53).

Stefano Mancuso (2013) en Sensibilidad e inteligencia en el mundo vegetal, comienza su análisis haciendo hincapié en el hecho de que en la Biblia "el hombre es el fruto supremo de los esfuerzos divinos, el elegido" (p. 9). En el Génesis, aparece al final de la Creación y todo está ya dispuesto para él, "listo para ser sometido y gobernado por el amo de todo lo creado" (p. 9). El hombre, no es nada más ni nada menos que una creación hecha a imagen y semejanza del mismo creador. Mancuso va a recurrir como ejemplo al episodio del Diluvio universal. Antes del mismo a Noé le es encomendado, obedeciendo el sagrado dictamen, cargar dentro del arca aves, animales y toda criatura animada por parejas, para así poder garantizar la reproducción de las especies y su continuidad posterior a la inundación. Mancuso se pregunta, entonces, “¿Y las plantas? No hay mención alguna a ellas" (p. 10). Sin embargo, es consciente que Noé sabe perfectamente que sin plantas no puede haber vida sobre la tierra y lo primero que hace, una vez libre, es plantar una viña. Beruete (2018) es categórico al respecto: "dependemos de las plantas en tantos sentidos que sería no solo erróneo sino también ingenuo considerarlas como formas inferiores de vida" (p. 43).

\footnotetext{
8 "No estamos seguros del poder de la naturaleza, su legitimidad, su realidad, y con razón. Quizás más que la mayoría, el jardinero o el granjero que su control [sobre la naturaleza] es siempre un tipo de ficción, que depende de la suerte y del clima y muchas otras cosas que están fuera de su control" [T. del A.]
} 
A partir del antropocentrismo del relato bíblico es que Jean-Marie Schaeffer (2009) desarrolla en El fin de la excepción humana el concepto del hombre como ser no natural, es decir, separado de la naturaleza, lo que el autor define como "ruptura óntica". Para explicarlo desarrolla una tesis en la que "el hombre es el origen de toda forma de razón" (p. 22), pero a su vez, es a partir de la razón que el hombre autoconstituye su validez. Siendo el hombre, entonces, el único poseedor de la facultad racional, "constituye el origen de toda validación" (p. 22), en especial de toda validación objetiva, que es, asegura Schaeffer, la forma racional que da al mundo ambiente. Pero si el hombre es constitutivamente sujeto, ocupa el lugar a partir del cual se constituye la objetividad. El sujeto es, por definición, conciencia y conciencia-de-sí, y si, como se mencionó anteriormente, el sujeto es quien constituye la objetividad, entonces "él es quien instituye autoconstituyéndose simultáneamente como conciencia-de-sí y conciencia de mundo" (p. 22). De esto se desprende el concepto de dualismo ontológico, que Schaeffer diferencia de la ruptura óntica, y es a partir del cual se definen dos planos del ser. Por un lado el material y por otro el espiritual, oponiendo, de este modo, no solo dos campos de lo viviente como sostiene el postulado de la ruptura óntica-entiéndase, lo humano por un lado y lo animal por otro-sino que esa dualidad reside en el interior del hombre mismo, creando múltiples oposiciones (cuerpo/alma, naturaleza/cultura, entre otras) que hacen, en definitiva, que el hombre se oponga a sí mismo (p. 25).

Ahora bien, Mancuso (2013) va a reconocer que el judaísmo, "pese a basarse en el Antiguo Testamento, prohíbe la destrucción gratuita de árboles y celebra su año nuevo (Tu Bishvat)" (p. 12). En esto, afirma, hay una ambivalencia: el hombre por un lado admite que no puede prescindir de las plantas pero al mismo tiempo no las reconoce. Ambivalencia que podría ponerse en entredicho con la lectura de Los gauchos judíos y las citas talmúdicas, en donde la importancia del mundo vegetal va más allá de la estrecha dependencia del hombre para su existencia, ya que existe además un mandato religioso de vivir de lo que uno mismo produce, de labrar su tierra, de cuidar de su ganado. Así es como lo ilustra el episodio en el que un viejo colono, rabí Guedalí, guiaba el arado cuando sus hijos y nietos debían de trazar los surcos iniciales de las amelgas. Para él se trataba de un "acto augural y solemne, y el anciano le daba el sentido religioso que este sencillo procedimiento tiene en el tratado agrícola del Talmud" (Gerchunoff, 2007, p. 152). No se cansaba de repetir que "es difícil sacar el pan de la tierra, pero sólo de la tierra lo sacan los hombres honrados. ¡Ojalá no hubieran tocado mis manos sino el misal y el arado, y estaría yo destinado a velar por vosotros en el Paraíso!" (p. 152). Por eso es que en el relato, la relación entre los judíos y la tierra representa más que una necesidad, es un ideal de existencia. Se puede ver ese dualismo óntico de Schaeffer presente en la relación entre el hombre y la tierra: por un lado lo natural, que es, sin el oxígeno y el alimento que proporcionan las plantas, el humano no puede vivir; y por otro, el espiritual, el mandato religioso de trabajar la tierra con el objeto de obtener la bendición divina.

\section{La amenaza del desierto: Delimitando el espacio de la colonia}

Luego del sosiego que disfrutaba la colonia, una amenaza externa pondrá en 
peligro las cosechas. Un buen día, una nube negra se hizo presente en el cielo. Parecía anunciar una lluvia que se avecinaba. Sin embargo, nadie en Rajil estaba preparado para lo que venía: "cayó sobre nosotros el vuelo pesado de la langosta" (Gerchunoff, 2007, p. 64). En poco tiempo toda la colonia judeoentrerriana se vio invadida: "El sol quedó oscurecido por la invasión espantosa y el paraíso, los postes de los corrales y el potrero se cubrieron de langosta, cuyo olor llenó la anchurosa campiña" (p. 64). Beruete (2018) sostiene que "hasta el más extraordinario de los jardines o el más natural de los parques empieza rápidamente a desfigurarse y termina pronto por desaparecer sin la atención continua" (p. 107), y Pollan (2001) agrega que "every advance in his control of the garden is also an invitation to a new disorder" (p. 367), dado que "wilderness might be reducible, acre by acre, but wildness is something else again"10 (p. 367). Con esta plaga, Gerchunoff está anticipando otra amenaza, y también viene de afuera.

La imagen del gaucho irrumpe tímidamente, primero con el personaje de Jacobo, mediante la descripción de su vestimenta: "El peoncito Jacobo, huérfano de la vecindad, trenza la cola del petizo amaestrado por él. Un poco de viento ondea sus bombachas y en el cinturón brillan el cabo de la daga y las diminutas boleadoras de plomo" (Gerchunoff, 2007, p. 53). Viste como un gaucho, lo que es impropio dentro de la comunidad judeoentrerriana. La abuela de la casa en la que Jacobo trabaja, doña Raquel, es una mujer arraigada a la tradición judía, característica en la que el narrador hace énfasis al mencionar el "pañuelo blanco que oculta su pelo blanco"; ese color blanco, presente de manera anafórica, parece querer representar tanto su edad madura como su pureza respecto a la tradición. Ella es la que le hará notar severamente a Jacobo que no debería estar haciendo ninguna actividad ese día: “¡Jacobo, deja el petizo. Hoy es sábado” (p. 53).

Varios aspectos en este breve pasaje que vale la pena resaltar. Jacobo es un "huérfano de la vecindad". Su orfandad no es un dato menor. Borges (2011) hacía notar, como característica del gaucho Martín Fierro la falta de padres, dado que "tenía que ser genérico para que todos pudieran identificarse con él" (p. 92). Asimismo, Martínez Estrada (1991) se refiere al gaucho como "hijo de nadie" y que ellos "no tenían hogar, eran los parias de la llanura, más parecidos al animal sin dueño que al hombre" (p. 69). A diferencia de los animales domesticados que vivían en la colonia que, como se vio anteriormente, parecían estar en comunión con los hombres y hasta habían aprendido a descansar el día de shabbath, Jacobo, sin embargo, un gaucho, no lo hace; es como si Gerchunoff lo quisiera mostrar, ya desde pequeño, como indomesticable. La abuela se resigna; en diálogo con el rabí Zacarías, que viene de visita y también le da una reprimenda a Jacobo por estar limpiando a su caballo, exclama: "Déjelo a ese gaucho; no sabe más que contestar. ¡No ve, todo un gaucho! Bombachas, cinturón, cuchillo y hasta esas cositas de plomo para matar perdices" (Gerchunoff, 2007, p. 55), y a esto añade: "en cambio, en la sinagoga, permanece mudo y no sabe rezar. ¡Educado por mi hijo el matarife y no sabe rezar!" (p. 55). Son pequeños detalles que van a retratar a la figura del gaucho, imagen que está muy vinculada a la que había demarcado Sarmiento

\footnotetext{
9 "todo avance en su control sobre el jardín es al mismo tiempo una invitación a un nuevo desorden" [T. del A.]

10“lo salvaje puede ser reducible, acre por acre, pero lo salvaje es otra cosa nuevamente" [T. del A.]
} 
(1985). La relación entre el gaucho y el caballo es inseparable, ya desde la niñez, dice Sarmiento, el gaucho es jinete apenas aprende a caminar (p. 33). Además, teniendo en cuenta el detalle que la abuela le reprocha, el de ser incapaz de seguir la tradición de la sinagoga, Martínez Estrada, en su descripción del perfil del gaucho, destaca que este

prefirió vivir en la vastedad de ese dominio sin capitular, sin someterse al arbitrio del otro advenedizo; amasó su conciencia con el paisaje, renegó de toda tradición y de ahí resultó el gaucho, el señor hambriento, el hombre de la tropa ignorante, proseguidor inarmónico de un sueño frustrado. (Martínez Estrada, 1991, p. 102)

"La vida del campo", sostiene Sarmiento, "ha desenvuelto en el gaucho las facultades físicas, sin ninguna de las de la inteligencia" (Sarmiento, 1985, p. 33).

Más adelante en el relato, doña Raquel y el rabí Zacarías empiezan a comentar lo sucedido en casa de Ismael Rudmann; su hija huye con un peón, con un gaucho. Acto que califican como "una vergüenza" (Gerchunoff, 2007, p. 55). En eso interviene Jacobo y sale en defensa de Remigio, el gaucho que había huido con la muchacha: "Es un guapo mozo. Me enseñó a enlazar y a domar" (p. 56), a lo que la abuela responde: “¡No ve! [...] para este renegado es lo mismo... como si se hubiera ido con un judío" (p. 56).

En este capítulo se marca claramente la condición de otredad, el gaucho como alteridad del judío. Se ha dicho que lo que el pueblo judío vino a buscar al territorio argentino era un espacio donde poder trabajar la tierra para cumplir con los mandatos de los escritos talmúdicos. Pero esto también se alinea con otro proyecto, un proyecto nacional, un modelo de nación que figuras como Alberdi y Sarmiento tenían en mente, siendo el desarrollo y la explotación de los elementos de riqueza que esconde el suelo argentino, el principal elemento de su engrandecimiento. Ese fue el gran aliciente para la inmigración extranjera y de ahí que se acuñara la máxima alberdiana: "gobernar es poblar". Para Alberdi, poblar formaba la sustancia de lo que él denominó "economía social", que significa instaurar ese "principal instrumento de la producción" allí donde no se había hecho aún, en lo que era conocido como "el desierto". No alcanza simplemente con ocupar un territorio desocupado, porque en realidad sí estaba ocupado, pero por la barbarie, lo que había que instalar, como sugiere Matías Farías, eran "agentes de moralización" (Alberdi, 2017, p. 22), inmigrantes que vinieran de las regiones de Europa que en la época eran considerados centros civilizados, y de ese modo, transplantar sus hábitos, costumbres y prácticas.

En este proyecto de país, el judío de la colonia de Rajil representaba al sujeto ideal, que se ceñían a la ley, tanto la de la nación que se pretendía construir, como la de los escritos rabínicos, por lo tanto era disciplinado, laborioso, tenía uso de razón, en él reinaba la mesura, la paz y la armonía con el entorno. Mientras que el gaucho, en cambio, era ingobernable, anárquico, salvaje, violento, en él no reinaba otra cosa que la ley de la selva, lo salvaje, la desmesura o lo arbitrario. Y esto no refleja otra cosa que la oposición entre civilización y barbarie. Cada uno de estos actores van a ocupar un espacio determinado en la novela, un espacio que va a estar continuamente en tensión. 
A través del relato, Gerchunoff va a delimitar el mapa del territorio entrerriano, teniendo a la colonia de Rajil en el centro. Esta viene a representar el espacio pastoril, siguiendo los paradigmas de Garrard, y en sus márgenes, va a estar rodeada por lo salvaje. Fuera de los límites de la colonia lo que hay es desierto. La colonia es aquel centro civilizado que resistía en el medio del desierto del que Sarmiento hace mención en Facundo:

El desierto las circunda a más o menos distancia: las cerca, las oprime; la naturaleza salvaje las reduce a unos estrechos oasis de civilización, enclavados en un llano inculto, de centenares de millas cuadradas, apenas interrumpido por una que otra villa de consideración. (Sarmiento, 1985, p. 29)

El desierto, espacio que empieza donde termina el poblado judeoentrerriano, es un territorio de wilderness, donde, según Garrard (2012), "combines connotations of trail and danger with freedom"11 (p. 68) y al mismo tiempo "advocates on a notion of the 'primal mind', which they contrast with the alienated 'civilized' mind" ${ }^{12}$ (p. 68). Representa el "tercer paisaje", como lo bautizó Clément Gilles, una tierra de nadie, fronteriza, sin cultivar ni urbanizar, "áreas residuales degradadas y marginales que, pese a ser espacios improductivos o baldíos, o tal vez por eso mismo, se convierten en refugios de la biodiversidad, nichos de las malas hierbas" (Beruete, 2018, p. 105). Cuando se dice que Remigio y la muchacha del rabí Ismael "huyen", lo que están diciendo es que se van de la comunidad pastoril para internarse en la periferia, se van, en otras palabras, al desierto. Desierto que es un espacio salvaje, donde todo resulta ingobernable, no se le teme a Dios ni se vive de acuerdo a su Ley, aspecto que el matarife añora de la ya lejana Rusia porque, sostenía, "aquí los jóvenes se vuelven unos gauchos" (Gerchunoff, 2007, p. 61).

Otros pasajes relevantes en el relato dan la pauta del espacio. Uno de ellos es en el que se describe la llegada de nuevos inmigrantes de Rusia, primer momento en que un grupo de la comunidad judeoentrerriana, desde su llegada, abandona el poblado para ir a la estación. "Debían llegar por el tren de las diez los inmigrantes para establecerse en un punto no lejano de San Gregorio, cerca del bosque, donde, según las leyendas del pago, se albergaban cuatreros y tigres" (p. 57). Más adelante, otro grupo de Rajil, luego de pasar por la sinagoga, deciden ir a la estación para intervenir en un pleito ocurrido en la vecindad. El narrador describe el camino de vuelta:

Regresamos en grupo. El cielo, bien azul, parecía más bajo, y detrás de las casas, blancas y limpias algunas, otras con las paredes de paja, las huertas florecían al sol, Pocos árboles había en la colonia y sólo frente a nuestra casa, un paraíso agrandaba su copa en una mancha de sombra sobre el camino. (Gerchunoff, 2007, p. 63)

Se puede apreciar como el paisaje es más bien salvaje, desparejo, en gran medida parece un yermo, una arboleda rala, sin protección contra el sol. Ya cuando

\footnotetext{
11 "combina connotación de amenaza y peligro con libertad" [T. del A.]

12 "aboga por una noción de la 'mente primitiva", que es puesta en contraste con la alienada 'mente civilizada"” [T. del A.]
} 
llegan a su casa, encuentran un lugar cultivado, con una vegetación cuidada, con una abundancia de árboles que garantizaba la sombra.

Los pajonales de San Gregorio pasan a ser conocido como terreno peligroso. En otro episodio, el joven Moisés partió una mañana montado a un caballo blanco y tomó el camino a San Miguel, sin su revólver. Se fue en dirección hacia el desierto, según las palabras de su madre, la señora Eva: "dicen que cerca de los campos de Ornstein merodean los bandidos" (Gerchunoff, 2007, p. 89). Ya entrada la noche la madre estaba preocupada; su hija intentó consolarla diciendo que en otra oportunidad, Moisés, en vísperas de Pascuas, había ido al bosque de San Gregorio y volvió recién al otro día trayendo la leña. Pero eso no sería consuelo para la madre ya que, asegura, aquella vez "llevaba revólver y, además, cerca de San Gregorio hay una colonia" (p. 90). En otras palabras, lo que preocupa a la madre es que esta vez no tiene territorio civilizado en las cercanías, está en el medio del desierto interminable, con el peligro que eso implica. Poco después se sintió el galope del caballo de Moisés, y luego se hizo visible lo que se temía: "sudoroso, se detuvo con el portón, sin el jinete, con la silla ensangrentada...” (p. 93).

Otros episodios se pueden encontrar en los que se enfatiza la relación de otredad entre el gaucho y el judío, en los que se puede ver una tensión irreconciliable entre ambos, incluso con escenas truculentas. Uno de ellos es el que se narran las desavenencias de Remigio Calamaco, al que Gerchunoff retrata como uno de los tipos más característicos de la colonia: "rugosa la cara, toda cubierta de cicatrices, larga la melena, larga la barba que el viento agitaba en el tranquilo galope de su pangaré" (Gerchunoff, 2007, p. 79). Fue soldado y refería sus proezas a los mozos judíos en las tertulias que celebraba. Añoraba los tiempos de juventud y veía con nostalgia a los "divididos predios, las enormes extensiones de tierra, alambrados por todas partes, su espíritu acostumbrado al comunismo de antes, se sentía oprimido en el nuevo régimen" (p. 80). Pero su suerte se selló cuando mató a su propio hijo porque en un duelo, este, dominado por su adversario, tuvo la mala idea de retroceder. Entonces don Remigio "le hendió con la daga en la cabeza, en un movimiento rápido" (p. 83). Esta reacción demuestra hasta qué punto la valentía tenía importancia para el gaucho. En un episodio posterior, Rabí Abraham es asesinado por su peón luego que le ordenara enyugar a uno de los bueyes y el peón le dijera que no era buena idea porque había trabajado toda la semana mientras que el otro estaba más descansado. Además, al peón ese buey no le gustaba porque, como más adelante confesaría, "se sale del surco a cada rato" (p. 87). El rabí no le hizo caso y el peón, en una reacción desmesurada, hundió su facón en el pecho del colono. En estos dos casos vemos a la violencia como respuesta ante la adversidad, reacciones que parecen no tener justificación alguna por su carácter de impulsivas, arbitrarias y, en definitiva, bárbaras, lo que, en gran medida, pasan a ser propias del comportamiento del gaucho.

Pero entonces, ¿por qué convivir con el gaucho? Porque es necesario. El otro es necesario. Los gauchos, como las malas hierbas, producen rechazo porque, siguiendo la analogía que plantea Beruete (2018), "auspician de incómodo recordatorio de la fragilidad del orden humano", que el pueblo de Rajil quería a toda costa mantener, a resguardo de la constante amenaza de la entropía y la fatiga del tiempo (p. 107). Eran necesarios porque, en el caso de Los gauchos judíos, 
conocían los oficios de la tierra, eran los que sabían los tiempos de la naturaleza, las estaciones, comprendían a las especies, así como los gauchos que describe Sarmiento (1985) poseían ese "saber otro". La increíble capacidad que tenía el rastreador de seguir las huellas de un animal, distinguirlas entre las otras, una "ciencia casera y popular" (p. 43), la habilidad del "gaucho malo" con el cuchillo o su capacidad para recorrer con su mente mil estancias de la pampa para tratar de encontrar un caballo de determinadas características, así como Napoleón conocía los nombres de los doscientos mil soldados que luchaban para él. Por más hiperbólica que sea la descripción sarmientina de las virtudes del gaucho, es importante destacar que si bien el saber erudito era imprescindible, el sujeto futuro, el que debía poblar los desiertos, debe conocer también el saber otro, algo que no estaba en los libros de los centros del pensamiento ilustrado europeo. La unión entre ambos saberes debía constituir el ser nacional.

En este tipo de literatura, a la que Juan Ignacio Oliva Cruz denomina "literatura del desarraigo" o del exilio, el fin último se encuentra en la construcción de una identidad híbrida. Por ejemplo, en el episodio de Rogelio Martínez y Miryam, ambos se entendían únicamente por medio del canto, ya que ella, recién llegada, no comprendía todavía el idioma. Rogelio era el gaucho cantor al que se refería Sarmiento. Según Gerchunoff, se trataba de un "eximio improvisador de vidalitas, sabía modularlas en los bailes campestres y arrancar, junto con los gemidos de su ilustre guitarra, lágrimas en las muchachas" (Gerchunoff, 2007, p. 75). Rogelio, garrido en su rudeza rural, era estimado por los israelitas del pueblo debido a su laboriosidad, y muy querido, sobre todo, por su patrón, Jacobo Jalerman, padre de Miryam. Lo curioso resultó que, a pesar de las diferencias lingüísticas y culturales, "cuando Rogelio entonaba una vidalita, ella, inevitablemete, respondía con un canto judío, extraño a los oídos del criollo, que se embelesaba oyéndola" (p. 76). Jacobo tenía la firme convicción de que esa unión era imposible y así lo expresaba: "Miryam no se casará con un cristiano; no tengan miedo" (p. 77). Pero por causa de las habladurías, don Jacobo acaba por despedir a Rogelio y poco después, y a la vista de todos los colonos, Rogelio y Miryam "pasaron como el viento" en su alazán, "erguido altivamente el criollo, y ella, suelta la cabellera, envolvía a toda la gente en una mirada de desafío" (p. 77) y cuando quisieron acordar, "la pareja fugitiva era un punto en la distancia" (p. 77).

Esta escena parece poner de manifiesto lo que Oliva Cruz (2010) llama la "paradoja del emigrante", esto es, "el ser capaz de conversar y debatir en su interior con opuestos culturales muchas veces excluyentes, cuando socialmente su conocimiento lingüístico y cultural de la tierra de acogida es limitado" (p. 303). De a poco se va a alcanzar esa hibridez, las alteridades se irán reconociendo y la tensión espacial que existía, empieza a ceder. El desierto empieza a dejar de ser un desconocido. Ese espacio que era propio del gaucho, alegóricamente representado por un paisaje "salvaje", empieza a ceder ante el otro espacio; ese espacio labrado, cultivado, que se encerraba dentro de los márgenes herméticos de la comunidad de Rajil. Gerchunoff en un momento nos ilustra al respecto del dualismo inherente en el ser humano, a partir de la Ley Escrita, la misma que, como vimos, impulsa al pueblo judío a cultivar la tierra, a vivir de los frutos por ellos cosechados: "Dice el Talmud [...] que dos fuerzas guían el alma de cada persona: el ángel bueno y la mala sombra, que en viejo hebreo se designa con el nombre de Satán. Ahora bien; 
no es posible negarlo. El Talmud lo dice con claridad" (p. 111).

Admiraban al gaucho así como le temían. Su leyenda estaba envuelta de heroísmo y barbarie. "Resultaba para el judío de Polonia o de Besarabia, el bandido romántico, feroz y caballeresco, como un héroe de Schummer, cuyas aventuras leían las muchachas obreras del taller, en Odessa, o al terminar las tareas de la colonia" (p. 155). Como advierte Beruete (2018), los defensores de las raíces colectivas con frecuencia olvidan que "los seres humanos no están anclados al suelo en el que nacieron, no tienen una identidad única y estática sino que fluida y mestiza" (p. 42) y de ahí que se pueda entender, finalmente, ese oxímoron que representa el título de la novela: Los gauchos judíos.

Las especies que sobreviven son las que mejor se saben adaptar al medio y Los gauchos judíos es, en definitiva, eso, una lección de supervivencia ejemplar de un pueblo que supo luchar en un medio hostil y salir adelante, encontrar un espacio para estar en comunión con la naturaleza en una relación de igualdad.

\section{Referencias}

Alberdi, J.B. (2017). Bases y puntos de partida para la organización política de la República Argentina (prólogo de Matías Farías). Buenos Aires, Argentina: Biblioteca del Congreso de la Nación.

Bachelard, G. (1978). El agua y los sueños. México, México: FCE.

Bacon, F. (1878) Novum Organum. Oxford, Reino Unido: Clarendon press.

Beruete, S. (2018). Verdolatría. Madrid, España: Turner.

Bolívar, S. (2009). Doctrina del Libertador. Caracas, Venezuela: Biblioteca Ayacucho.

Borges, J.L. (2011). Obras completas 4. Buenos Aires, Argentina: Sudamericana.

Gilles, C. (2007). Manifiesto del tercer paisaje. Barcelona, España: Gmínima.

Garrard, G. (2012). Ecocriticism. New York, Estados Unidos: Routledge.

Gerchunoff, A. (2007). Los gauchos judíos. El hombre que habló en la Sorbona. Buenos Aires, Argentina: Biblioteca Nacional.

Llarena, A. (2002). "Espacio y literatura en Hispanoamérica”. En J. de Navascués y Martín (Ed.), De Arcadia a Babel: naturaleza y ciudad en la literatura hispanoamericana (pp. 41-58). Madrid, España: Iberoamericana.

Mancuso, S., Viola, A., \& López, D. P. (2015). Sensibilidad e inteligencia en el mundo vegetal. Barcelona, España: Galaxia Gutenberg. 
Martínez Estrada, E. (1991). Radiografía de la pampa. Buenos Aires, Argentina: Losada.

Oliva Cruz, J.I. (2010). "Poéticas del paisaje y el territorio en la literatura del desarraigo". En C.F. Junqueras (Ed.), Ecocríticas. Literatura y medio ambiente (pp. 293-312). Madrid, España: Iberoamericana.

Pollan, M. (2001). The Botany of Desire. Toronto, Canadá: Random House.

Sarmiento, D. F. (1985). Facundo. Caracas, Venezuela: Biblioteca Ayacucho.

Schaeffer, J.M. (2009). El fin de la excepción humana. Buenos Aires, Argentina: FCE.

Slawinski, J. (1989). El espacio en la literatura: distinciones elementales y evidencias introductorias. Textos y contextos (pp. 265-287). La Habana,Cuba: Criterios. 